\title{
PERKEMBANGAN EKOSISTEM DAN POTENSI KARET UNTUK REKLAMASI LAHAN BEKAS TAMBANG BATUBARA
}

\author{
Ecosystem Development And Rubber Potential For Reclamation Of Coal Mining Mine \\ Junaidi, Atminingsih, dan Radite Tistama \\ Balai Penelitian Sungei Putih, PO. BOX. 1415 Medan 20001 \\ Email : atminingsih85@gmail.com
}

Diterima 9 Agustus 2017 / Direvisi 13 Oktober 2017 / Disetujui 31 Desember 2017

\begin{abstract}
Abstrak
Kegiatan pertambangan batubara terbuka menimbulkan degradasi lahan yang berat dan merubah komposisi ekosistem. Artikel ini merangkum beberapa studi mengenai perkembangan ekosistem dan upaya revegetasi lahan bekas tambang batubara di kawasan Asia. Reklamasi biologis dalam jangka pendek bermanfaat untuk mengurangi erosi, dan dalam jangka panjang berguna mengembalikan keseimbangan ekologis antara lahan bekas tambang dan wilayah sekitarnya. Jenis rumput-rumputan umumnya mendominasi tahap awal suksesi kemudian akan digantikan oleh jenis tumbuhan semak dan pohon pada tahap akhir suksesi. Bebebapa family dominan ditemukan di lokasi bekas tambang batubara antara lain: Apocynaceae, Fabaceae, Moraceae, Poaceae, Euphorbiaceae, Asteraceae dan Lamiaceae. Tumbuhan asli daerah setempat dapat digunakan untuk mempercepat proses perkembangan ekosistem dan memfasilitasi suksesi tanaman secara alami. Perkembangan ekosistem dipengaruhi jenis tanah, iklim, dan spesies indigenous sekitar yang beragam. Studi mengenai perkembangan ekosistem di wilayah yang memiliki karakteristik spesifik diperlukan untuk meningkatkan keberhasilan reklamasi. Karet memiliki potensi untuk revegetasi lahan bekas tambang batubara, melalui proses perbaikan ekosistem tanah untuk membentuk lingkungan tumbuh yang mendukung pertumbuhan tanaman karet.
\end{abstract}

Kata kunci: karet, tambang batubara, reklamasi, revegetasi, ekosistem, suksesi

\section{Abstract}

Opencast coal mining rise a massive land degradation and changed ecosystem composition. This article reviewed some studies in efforts for coal mining revegetation in Asia. Biological reclamation in short period mitigate the soil erosion, and in long period used for rebalancing of ecological between exmining land with the around area. Grass species dominated in the first succession periode, and changed with some scrubs and trees in advance period. Several families dominated ex-coal mining such as: Apocynaceae, Fabaceae, Moraceae, Poaceae, Euphorbiaceae, Asteraceae and Lamiaceae. The native plant of around mining area can be use to accelarate ecosystem development and facilited plants succession naturally. Ecosystem development was affected by kind of soil, climate, and diversity of species indigenous. Study of ecosystem development in specific area has to be done for increased successfull reclamation. Rubber tree has high potential for revegetation ex coal mining area, through soil ecosystem improvement to supported rubbertree growth.

Keywords: hevea, coal mining, reclamation, revegetation, ecosystem, succestion.

\section{Pendahuluan}

Batubara mensuplai 30\% dari kebutuhan energi global. Pada tahun 2014, total produksi batubara di seluruh dunia mencapai 8.022 Mt. Sepuluh negara penghasil batubata terbesar di dunia adalah China (3.747,5 Mt), Amerika Serikat $(8.075,5 \mathrm{Mt})$, India $(668,4 \mathrm{Mt})$, Australia (491,2 Mt), Indonesia (470,8 Mt), Rusia (334,1 Mt), Afrika Selatan (253,2 Mt), 
Jerman (186,5 Mt), Polandia (137,1 Mt), dan Kazakstan (115,5 Mt) (World Coal Association, 2015). Kegiatan penambangan batubara terutama dengan sistem terbuka (opencast mining) yang menimbulkan kerusakan lingkungan yang parah terutama disebabkan oleh kontaminasi dan degradasi lahan. Kerusakan tersebut disebabkan operasional penambangan terutama penggalian dan pemindahan top soil dalam jumlah besar (Juwarkar \& Jambhulkar, 2008).

Masalah lingkungan yang ditimbulkan oleh penambangan batubara antara lain penurunan permukaan tanah, kerusakan lingkungan perairan, pembuangan limbah tambang, dan polusi udara (Zhengfu et al., 2010). Di beberapa tempat, penambangan batubara juga dapat mengakibatkan tanah longsor, lubang dan retakan di permukaan tanah serta bagunan di sekitar tambang (Ardebili et al., 2011). Bahan-bahan metal yang digunakan selama proses penambangan seperti $\mathrm{Mn}, \mathrm{Zn}, \mathrm{Pb}, \mathrm{As}$, $\mathrm{Fe}, \mathrm{Sr}$, dan $\mathrm{Nb}$ juga dilaporkan dapat mencemari lahan-lahan pertanian di sekitarnya (Bhuiyan et al., 2010).

Dengan manajemen yang buruk, kerugian ekologis dan lingkungan yang ditimbulkan oleh kegiatan penambangan batubara dapat jauh lebih tinggi dibanding keuntungan ekonomi yang diperoleh. Sebuah studi yang dilakukan Li et al. (2011) menunjukkan bahwa nilai ekonomi dari batu bara yang ditambang di Distrik Mentougou, China sekitar US\$ 870 juta, sedangkan kerugian lingkungan yang timbul dari kegiatan penambangan diperkirakan mencapai US\$2001 juta dalam kurun waktu 50 tahun. Kerugian lingkungan yang utama adalah hilangnya daya dukung lingkungan akibat limbah batubara, saluran pembuangan, kehilangan air bersih dan tanah akibat erosi.

Reklamasi dan revegetasi memiliki dampak yang signifikan terhadap pemulihan lahan bekas tambang (Sudarmadji \& Hartati, 2016). Dalam jangka pendek, reklamasi biologis tersebut bertujuan untuk mengendalikan erosi secara cepat melalui pertumbuhan tanaman cepat yang sekaligus berperan sebagai kolonisator awal. Tujuan jangka panjang adalah menciptakan keseimbangan ekologis (tanah bekas tambang, mikroflora, mikro fauna, dan tanaman" antara lahan bekas tambang dengan lingkungan sekitarnya (Maiti, 2013). Meskipun demikian, perkembangan ekosistem dapat berbeda pada jenis tanah, iklim, dan spesies indigenus sekitar yang berbeda.

Artikel ini merangkum beberapa penelitian yang telah dilakukan terkait perkembangan ekosistem dan upaya revegetasi lahan bekas tambang batubara di Asia. Kemiripan iklim, kondisi tanah serta species flora dan fauna melatarbelakangi region ini menjadi rujukan dalam tulisan ini meskipun perbedaan karakteristik lahan yang mencolok dalam region ini sangat mungkin dijumpai. Diharapkan artikel ini dapat melengkapi pengetahuan tentang reklamasi lahan-lahan terdegradasi tidak hanya dari sisi perbaikan lingkungan tumbuh secara fisik dan kimia, tetapi juga dari sudut pandang ekologi dan keseimbangan ekosistem sekitar.

\section{Karakteristik Lahan Bekas Tambang Batubara di Asia}

Lahan bekas tambang umumnya hanya memiliki lapisan tanah yang tipis atau tidak sama sekali (Maiti, 2013). Ciri lainnya adalah lahan umumnya didominasi campuran pecahan batu dan batubara, drainase yang buruk, kadar air tanah rendah, tanah padat (compacted), temperatur tanah tinggi (Zhenqi et al., 2012), kadar bahan organik, nutrien dan aktivitas mikroorganisme rendah serta rentan terhadap erosi dan polusi air dan udara (Ekka \& Behera, 2011). Aktivitas penambangan batubara mempengaruhi kualitas air dan tanah di sekitarnya(Harun-Or-Rashid et al., 2014).

Jha \& Singh (1991) membandingkan karakteristik lahan bekas tambang dengan hutan alami yang ada di sekitarnya di Jhingurda, Madya Pradesh, India. Hasil penelitian tersebut menunjukkan bahwa sifatsifat fisik, kimia dan biologis lahan bekas tambang berubah menjadi lebih baik seiring waktu (Tabel 1). Proporsi pecahan kasar lebih tinggi di lahan bekas tambang dibandingkan 
dengan hutan alami namun proporsi tersebut menurun seiring waktu, demikian halnya dengan kadar $\mathrm{Na}$. Total $\mathrm{N}$, mineral $\mathrm{N}$, $\mathrm{NaHCO}_{3}$-Pi dan $\mathrm{K}$ lebih rendah dibandingkan hutan alami namun terus meningkat seiring dengan waktu.

Lahan yang berasal batubara muda bersifat sangat asam karena oksidasi sulfur yang bereaksi dengan air hujan menghasilkan asam sulfur. Keasaman lahan meningkat seiring dengan waktu dan mencapai maksimum dalam lima tahun sehingga menghambat pertumbuhan tanaman, daya tahan dan pembentukan ekosistem pada lahan-lahan bekas tambang batubara yang baru (Hazarika et al., 1996). Beberapa bahan telah dicoba untuk remediasi lahan bekas tambang batubara antara lain limbah industri kapur (Yang et al., 2006) dan abu (Jala \& Goyal, 2006).

\section{Perkembangan Ekosistem di Lahan Bekas Tambang Batubara}

Jenis spesies tumbuhan di lahan bekas tambang batubara menurun tajam keragamannya dibanding dengan hutan di sekitarnya (Lee et al., 2002; Panda et al., 2014). Kegiatan pertambangan dapat merubah komposisi ekosistem. Solviana et al. (2012) membandingkan komposisi dan struktur kecambah (seedling) dan tanaman muda (sapling) sebelum dan sesudah kegiatan penambangan di Sumatera Barat, Indonesia. Hasil penelitian tersebut menunjukkan penurunan komposisi, indeks keragaman dan kesamaan. Nilai penting tertinggi juga mengalami perubahan, sebelum kegiatan penambangan kopi hutan (Canthium dicoccum) memiliki nilai penting seedling tertinggi, sedangkan setelah penambangan putihan (Clibadium surinamense) menempati nilai penting tertinggi. Tanaman muda (sapling), sebelum panambangan nilai tertinggi adalah karet (Hevea brasiliensis) sedangkan setelah penambangan mara (Macaranga tanarius). Baon et al. (2014) melaporkan bahwa spesies yang mengkolonisasi lahan bekas tambang di Kalimantan Timur, Indonesia antara lain tumbuhan mejalar, semak, dan beberapa spesies pohon yang kurang memiliki nilai ekonomis.

Perkembangan ekosistem dan dominasi spesies dapat berbeda antara satu wilayah dengan wilayah lainnya namun pola suksesi alami umumnya sama. Hazarika et al. (2006) mempelajari kolonisasi alami di lahan tambang batubara di Assam, India dan menemukan bahwa pada tahap awal suksesi komponen vegetasi yang mendominasi adalah

Tabel 1. Nilai rata-rata dari beberapa sifat fisik dan kimia tanah dari hutan alami dan lahan bekas tambang batubara.

\begin{tabular}{|c|c|c|c|c|c|}
\hline \multirow[t]{2}{*}{ Karakteristik } & \multirow{2}{*}{$\begin{array}{l}\text { Tanah hutan } \\
\text { alami }\end{array}$} & \multicolumn{4}{|c|}{$\begin{array}{l}\text { Lahan bekas tambang } \\
\text { (umur dalam tahun) }\end{array}$} \\
\hline & & 5 & 10 & 16 & 20 \\
\hline \multicolumn{6}{|l|}{ Tekstur tanah (\%) } \\
\hline$>2,0 \mathrm{~mm}$ & 8,0 & 25,0 & 23,0 & 20,0 & 18,0 \\
\hline $2-0,2 \mathrm{~mm}$ & 64,0 & 61,0 & 63,0 & 56,0 & 60,0 \\
\hline $0.2-0,1 \mathrm{~mm}$ & 14,0 & 5,0 & 6,0 & 10,0 & 10,0 \\
\hline$<0,1 \mathrm{~mm}$ & 14,0 & 9,0 & 8,0 & 14,0 & 12,0 \\
\hline $\mathrm{pH}$ & 6,4 & 6,3 & 6,2 & 6,5 & 6,8 \\
\hline Daya pegang air (\%) & 52,0 & 52,0 & 45,0 & 48,0 & 50,0 \\
\hline Gravimetri air tanah (\%) & 8,6 & 4,6 & 2,9 & 2,6 & 5,4 \\
\hline Total N tanah (\%) & 0,291 & 0,068 & 0,074 & 0,082 & 0,086 \\
\hline Mineral N $\left(\mu \mathrm{g} \mathrm{g}^{-1}\right)$ & 16,4 & 5,8 & 7,6 & 9,9 & 15,6 \\
\hline $\mathrm{NaHCO}_{3}-\mathrm{Pi}\left(\mu \mathrm{g} \mathrm{g}^{-1}\right)$ & 15,0 & 5,0 & 7,3 & 8,4 & 8,9 \\
\hline $\mathrm{Na}\left(\mu \mathrm{g} \mathrm{g}^{-1}\right)$ & 35,0 & 115,0 & 97,0 & 71,0 & 64,0 \\
\hline $\mathrm{K}\left(\mu \mathrm{g} \mathrm{g}^{-1}\right)$ & 264,0 & 35,0 & 49,0 & 63,0 & 74,0 \\
\hline
\end{tabular}

Dimodifikasi dari Jha \& Singh, 1991 
jenis rumput-rumputan. Spesies semak dan pohon dominan pada lahan yang lebih lama, pada saat rumput-rumputan telah ternaungi dan tidak dapat berkompetisi dengan spesies tahunan. Di lingkungan tropis kering di India, tumbuhan tapak jalak (Dactyloctenium aegyptium), Aristida adscensionis dan rumput cakar ayam (Digitaria setigera) merupakan kolonisator-kolonisator awal pada lahan bekas tambang berumur lima tahun. Spesies-spesies tersebut kemudian digantikan oleh komunitas Aristida adscensionis, rumput embun (Bothriochloa pertusa), dan tapak jalak (Dactyloctenium aegyptium) (Jha \& Singh, 1991). Hal ini juga didukung oleh penelitian Panda et al. (2014) yang menunjukkan bahwa pada lahan bekas tambang yang sudah lama, komposisi floristik alami didominasi oleh spesies pohon dikuti kemudian oleh jenis semak dan rumput-rumputan. Beberapa famili yang dominan antara lain Apocynaceae, Fabaceae, Moraceae, Poaceae, Euphorbiaceae, Asteraceae dan Lamiaceae.

Struktur dan komposisi ekosistem berubah selama proses suksesi. Penelitian Li et al. (2008) di Shanxi, China menemukan beberapa spesies pionees antara lain: Setaria viridis, Amaranthus retroflexus, Tribulus terreste, Artemisia gmelinii, Bothriochloa ischaemum, Periploca sepium, Lespedeza daurica, Vitex negundo, Ailanthus altissima dan Robinia pseudoacacia. Spesies-spesies tersebut berhasil mengkoloni dan berperan penting dalam restorasi vegetasi di lahan bekas tambang. Lee et al. (2002) menyarankan agar menggunakan spesies yang diperoleh dari lapisan atas tanah hutan di perbatasan tambang dan hutan alami di sekitarnya.

Untuk mencapai ekosistem yang stabil, pada tahap awal suksesi diperlukan pembangunan komunitas mikoriza. Harris (2009) menyatakan bahwa komunitas mikoriza dapat meningkatkan pembentukan, daya tahan, dan keberhasilan spesies lanjutan yang diinginkan untuk mengkolonisasi lahan bekas tambang. Sebaliknya, spesies suksesi awal dapat menentukan perkembangan populasi jamur mikoriza (Mehrota, 1998). Penelitian Ekka \& Behera (2010) di Orissa,
India meunjukkan bahwa di antara spesies rumput-rumput yang diamati, Cynodon dactylon memiliki infeksi mikoriza tertinggi sedangkan terendah yaitu Cyperus metzii.

\section{Spesies Pohon Untuk Reforestrasi}

Penanaman pohon dapat mempercepat perbaikan tanah secara signifikan pada lahan bekas tambang (Sing \& Singh, 2006). Revegetasi juga dapat memfasilitasi suksesi tanaman secara alami. Banarjee et al. (2004) menyatakan bahwa lingkungan yang buruk dapat diperbaiki secara bertahap melalui penanaman spesies yang sesuai. Penanaman spesies pohon Acacia mangium, A. hobserecia, Dalbergia sissoo, Albizia procera, Pithecelbbium dulce, Acacia auriculiformis, Acacia nilotica, dan Gmelina arbórea menunjukkan bahwa jumlah kolonisator alami, status nutrien dan karbon organik meningkat dengan bertambahnya umur tanaman.

Bohre \& Chaubey (2014) menyatakan bahkan restorasi berbasis ekosistem (ecorestoration) melalui penanaman tanaman hutan dapat menjadi upaya yang efektif untuk reklamasi ekosistem terdegradasi. Restorasi dengan menggunakan campuran enam spesies tanaman hutan (Dalbergia sissoo, Pongamia pinnata, Tectona grandis, Gmelina arborea, Azadirachta indica dan Cassia siamea) di Singrauli, India menunjukkan bahwa kepadatan massal (bulk density) secara bertahap menurun, sedangkan karbon organik, tingkat kemasaman, konduktivitas elektron, daya pegang air dan status hara meningkat demikian juga biomassa mikroorganisme (Tabel 2).

Dalam reklamasi lahan terdegradasi, spesies asli setempat (native species) lebih baik dibanding spesies dari luar (exotic species) karena lebih sesuai terkait ekosistem dan iklim. Meskipun demikian, spesies eksotis yang memiliki pertumbuhan cepat terkadang diperlukan untuk menutup permukaan tanah dengan cepat.

Beberapa spesies eksotis seperti Eucalyptus hybrid, Acacia auriculiformis, dan Casuarina equisetifolia dilaporkan sesuai untuk restorasi di 
Tabel 2. Perkembangan biomassa mikroorganisme pada restorasi lahan bekas tambang menggunakan beberapa spesies tanaman hutan

\begin{tabular}{lcccc}
\hline \multicolumn{1}{c}{ Spesies } & $\begin{array}{c}\text { Umur } \\
\text { tanaman } \\
\text { (tahun })\end{array}$ & $\begin{array}{c}\text { Biomassa } \\
\text { mikroba } \\
(\mathrm{mg} / \mathrm{kg})\end{array}$ & $\begin{array}{c}\text { Umur } \\
\text { tanaman } \\
\text { (tahun) }\end{array}$ & $\begin{array}{c}\text { Biomassa } \\
\text { mikroba } \\
(\mathrm{mg} / \mathrm{kg})\end{array}$ \\
\hline Tectona grandis & 2 & 40,2 & 18 & 51,5 \\
Dalbergia sissoo & 2 & 32,5 & 18 & 66,6 \\
Azadirachta indica & 2 & 21,2 & 18 & 52,7 \\
Cassia siamea & 2 & 35,5 & 19 & 50,3 \\
Pongamia pinnata & 2 & 24,2 & 18 & 54,7 \\
Gmelina arborea & 6 & 31,7 & 10 & 42,6 \\
\hline
\end{tabular}

Dimodifikasi dari Bohre \& Chaubey, (2014)

Singrauli, India (Dutta \& Agrawal, 2003). Singh \& Singh (2006) mensintesis beberapa penelitian restorasi di wilayah tropis beriklim kering di India dengan menggunakan spesies pohon lokal. Hasil kajian tersebut menyimpulkan bahwa penanaman langsung menggunakan biji Zizyphus jujube, Pongamia pinnata, dan Syzygium cumini sangat baik digunakan di lahan datar, sedangkan Azadirachta indica dan Terminalia arjuna sesuai untuk lahan miring. Modifikasi lingkungan tumbuh seperti pembuatan terasan di lahan berbukit diperlukan untuk meningkatkan keberhasilan reklamasi (Zhenqi et al., 2012).

Di Kalimantan Timur, uji coba penanaman kakao di lahan bekas tambang telah dilakukan sebagaimana dilaporkan oleh Baon et al. (2014). Han et al. (2004) melaporkan bahwa Betula schrnidtii dapat tumbuh baik di lahan bekas tambang batubara yang telah diabaikan di Taebaek, Korea Selatan dengan penambahan unsur hara yang sesuai. Sudarmaji \& Hartati (2016) menyarankan pemulihan ekosistem dapat dilakukan oleh spesies yang memiliki pertumbuhan cepat yang meliputi peningkatan kapasitas infiltrasi, penurunan run-off permukaan dan tingkatan erosi, perbaikan lingkungan sebagai habitat untuk spesies pendatang. Singh et al. (2000) menyatakan pemilihan jenis pohon yang akan digunakan perlu dilakukan secara ilmiah. Pohon yang ditanam harus dapat meminimalkan erosi, menyetabilkan pecahan tambang dan meningkatkan status hara dan potensi kesuburan lahan. Perusahan pertambangan disarankan untuk mengadopsi strategi reklamasi dan revegetasi untuk merehabilitasi lahan bekas tambang serta merestorasi produktivitas dan stabilitas tanah.

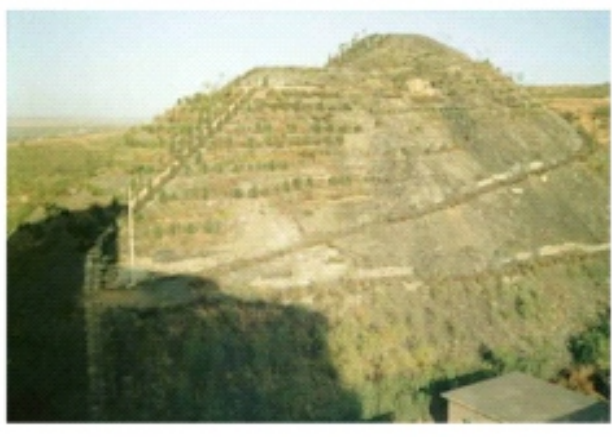

a

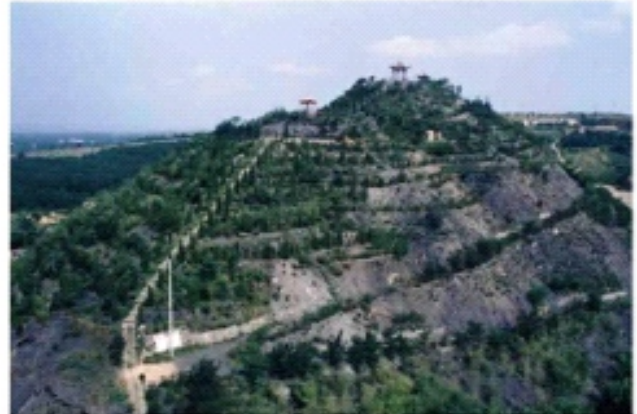

b

sumber: Zhenqi et al. (2012).

Gambar 1. Penghutanan kembali lahan bekas tambang batubara di Wangzhuang, China, foto diambil pada 1991 (a) dan 1994 (b) (sumber: Zhenqi et al. (2012). 


\section{Potensi Tanaman Karet Untuk Reklamasi Lahan Bekas Tambang Batu Bara}

Studi yang dilakukan Adman et al. (2010) di beberapa lahan tambang batubara di Kalimantan Selatan menunjukkan bahwa sampai 5 - 6 tahun pelaksanaan reklamasi tidak terjadi peningkatan kualitas sifat kimia tanah. Jenis tanaman yang digunakan untuk revegetasi tidak berpengaruh nyata terhadap kualitas tanah dalam jangka waktu tersebut. Di samping itu, vegetasi yang tumbuh secara alami lebih dominan dalam kuantitas maupun keragaman spesies dibanding tanaman yang diintroduksi. Hal ini menunjukkan bahwa identifikasi vegetasi lokal perlu dilakukan dengan analisis vegetasi dan menghitung indeks nilai penting (INP) spesies tumbuhan di hutan sekitar lahan tambang. Adman et al. (2012) menyarankan pemilihan jenis pohon untuk revegetasi harus memperhatikan tujuh kriteria yaitu habitus, habitat, kemampuan regenerasi, nilai ekonomis, nilai ekologis, simbiosis dan kemampuan trubusan.

Revegetasi lahan bekas tambang batubara terutama terkendala oleh kadar air tanah yang sangat rendah. Sarman et al. (2015) menyarankan penggunaan retardan seperti paclobutrazol dan cycocel pada bibit karet yang digunakan untuk revegetasi. Hal tersebut didasari kemampuan retardan tersebut dalam meningkatkan toleransi tanaman terhadap cekaman kekeringan melalui mekanisme penghambatan pertumbuhan vegetatif tanpa menyebabkan pertumbuhan abnormal.

Penelitian Sembiring et al. (2016) menunjukkan bahwa penggunaan bakteri pereduksi sulfat mempengaruhi karakteristik kimia tanah tambang batubara dan berpengaruh positif terhadap pertumbuhan tanaman karet dan penutup tanah Mucuna bracteata di polibeg dalam skala rumah kaca. Penambahan bahan organik meningkatkan populasi mikroba tanah. Pemberian biofertilizer mampu meningkatkan jumlah bakteri pemantap agregat, pelarut fosfat, dan penambat $\mathrm{N}$ non-simbiotik (Istianto et al., 2009). Perlakuan kombinasi pupuk, kompos dan biofertilizer dapat meningkatkan $\mathrm{pH}$, kandungan nitrogen dan fosfat (Tistama et al., 2009) pada uji coba di rumah kaca.

\section{Kesimpulan}

Reklamasi dan revegetasi adalah cara terbaik untuk memperbaiki dan mengembalikan fungsi lahan bekas tambang batubara. Di samping manipulasi lingkungan tumbuh agar sesuai dengan tanaman lanjutan yang diintroduksi, proses suksesi alami dan kondisi lingkungan yang mendukung suksesi alami perlu diperhatikan. Pada tahap awal suksesi, ekosistem didominasi oleh spesies rumput-rumputan kemudian digantikan oleh spesies semak dan pohon. Pemilihan species kolonisator dan tanaman lokal dapat menjadi kunci keberhasilan reklamasi. Sejauh ini penggunaan tanaman karet untuk revegetasi lahan bekas tambang batubara belum menunjukkan keberhasilan yang signifikan. Namun demikian, dengan pendekatan ekologi dan manipulasi mikroba tanah, potensi tanaman karet untuk revegetasi tetap terbuka lebar.

\section{Daftar Pustaka}

Adman, B., Hendrarto, B., \& Sasongko, D. P. (2012). Pemilihan jenis pohon lokal cepat tumbuh untuk pemulihan lingkungan lahan pascatambang batubara (Studi Kasus di PT. Singlurus Pratama, Kalimantan Timur). Jurnal Ilmu Lingkungan, 10(1), 19-25. doi:10.14710/jil.10.1.19-25

Adman, B., Wawan, G., \& Septina, A. W. (2010). Kajian teknik reklamasi dan jenis tanaman revegetasi terhadap sifat fisik, kimia, dan biologi tanah pada lahan eks-tambang batubara: Laporan Hasil Penelitian 2010. Diakses dari Balai Penelitian Teknologi Perbenihan Samboja, Kutai Kartanegara.

Ardebili, L., Babazadeh, V., Mammadov, M., \& Navi, P. (2011). Physical environment pollution of mining coal in Central Alborz (Northern Iran). World Applied Sciences Journal, 14(8), 1141-1145. 
Banerjee, S. K., Mishra, T. K., Singh, A. K., \& Jain, A. (2004). Impact of plantation on ecosystem development in disturbed coal mine overburden spoils. Journal of Tropical Forest Science, 16(3), 294-307.

Baon, J., Prawoto, A., Wibawa, A., \& Abdoellah, S. (2014). Increasing cocoa productivity and farmer capacity in surrounding area of PT Kaltim Prima Coal and PT Berau Coal. Journal of Degraded and Mining Lands Management, 1(2), 97-104.

Bhuiyan, M. A. H., Parvez, L., Islam, M. A., Dampare, S. B., \& Suzuki, S. (2010). Heavy metal pollution of coal mine-affected agricultural soils in the northern part of Bangladesh. Journal of hazardous materials, 173(1-3), 384-392.

Bohre, P., \& Chaubey, O. P. (2014). Restoration of degraded lands through plantation forests. Global Journal of Science Frontier Research: Biological Science, 14(1), 19-27.

Dutta, R. K., \& Agrawal, M. (2003). Restoration of opencast coal mine spoil by planting exotic tree species: a case study in dry tropical region. Ecological Engineering, 21(2-3), 143-151.

Ekka, N. J., \& Behera, N. (2010). A study of the mycorrhizal association with vegetation on coal mines spoil. Bioscan, 5(3), 369-372.

Ekka, N. J., \& Behera, N. (2011). Species composition and diversity of vegetation developing on an age series of coal mine spoil in an open cast coal field in Orissa, India. Tropical Ecology, 52(3), 337-343.

Han, S.-H., Lee, J.-C., Jang, S.-S., \& Kim, P.-G. (2004). Composted sewage sludge can improve the physiological properties ofBetula schmidtii grown in tailings. Journal of Plant Biology, 47(2), 99-104.

Harris, J. (2009). Soil microbial communities and restoration ecology: facilitators or followers? Science, 325(5940), 573-574.

Harun-Or-Rashid, H. M., Urbi, Z., \& Islam, M. (2014). Environmental impact of coal mining: a case study on the Barapukuria coal mining industry, Dinajpur, Bangladesh. Middle-East Journal of Scientific Research, 21(1), 268-274.
Hazarika, P., Talukdar, N., \& Singh, Y. (1996). Difficulty in restoration of vegetation in coal mine overburden spoils, Margherita, Assam: Role of vesicular arbuscular mycorrhizae Abstract of Papers, Annual Technical Session, Assam Science Society (pp. 42).

Hazarika, P., Talukdar, N., \& Singh, Y. (2006). Natural colonization of plant species on coal mine spoils at Tikak Colliery, Assam. Tropical Ecology, 47(1), 37-46.

Istianto, Munthe, H., Tumpal, H. S. S., Radite, T., \& Nugroho, P. A. (2009, 4- 6 Agustus). Pemulihan lahan bekas tambang batubara melalui pengusahaan tanaman karet. Tulisan disajikan pada Prosiding Lokakarya Nasional Pemuliaan Tanaman Karet 2009, Batam.

Jala, S., \& Goyal, D. (2006). Fly ash as a soil ameliorant for improving crop production-a review. Bioresour Technol, 97(9), 1136-1147.

Jha, A., \& Singh, J. (1991). Spoil characteristics and vegetation development of an age series of mine spoils in a dry tropical environment. Vegetatio, 97(1), 6376.

Juwarkar, A. A., \& Jambhulkar, H. P. (2008). Phytoremediation of coal mine spoil dump through integrated biotechnological approach. Bioresour Technol, 99(11), 47324741.

Lee, J., Han, S., Jang, S., Lee, J., Kim, P., Hur, J., \& Yum, K. (2002). Selection of indigenous tree species for the revegetation of the abandoned coal mine lands in Taeback Area. Korean Journal of Agricultural and Forest Meteorology, 4(2), 86-94.

Li, F., Liu, X., Zhao, D., Wang, B., Jin, J., \& $\mathrm{Hu}$, D. (2011). Evaluating and modeling ecosystem service loss of coal mining: a case study of Mentougou district of Beijing, China. Ecological Complexity, 8(2), 139-143.

Li, S., Yang, B., \& Wu, D. (2008). Community succession analysis of naturally colonized plants on coal gob piles in Shanxi mining areas, China. Water, Air, and Soil Pollution, 193(1-4), 211-228. 
Maiti, S. K. (2013). Ecorestoration of the coalmine degraded lands. New Delhi, India: Springer India.

Mehrotra, V. (1998). Arbuscular mycorrhizal associations of plants colonizing coal mine spoil in India. The Journal of Agricultural Science, 130(2), 125-133.

Panda, S., Minz, A. P., \& Dhal, N. (2014). Floristic studies of Lajkura coal mines area Jharsuguda, Odisha: an overview. International Journal of Scientific and Research Publication, 4(12), 1-11.

Sarman, Z. R., Djafar, Yakup, \& Suryaningtyas, H. (2015). The provision of rubber seedling for coal post-minig land revegetation with the application of retardant: a review. International Journal of Current Research in Biosciences and Plant Biology, 2(7), 58-62.

Sembiring, Y. R. V., Andriyanto, M., Siagian, N., Enny, W., \& Azwir. (2016). Isolasi dan pemanfaatan bakteri pereduksi sulfat untuk memperbaiki sifat kimi tanah bekas tambang batubara serta pengaruhnya terhadap pertumbuhan karet (Hevea brasiliensis) di polibeg: Laporan Akhir Penelitian 2016. Diakses dari Balai Penelitian Sungei Putih, Medan.

Singh, A., \& Singh, J. (2006). Experiments on ecological restoration of coal mine spoil using native trees in a dry tropical environment, India: a synthesis. New Forests, 31(1), 25-39.

Singh, R. S., Singh, T. B., \& Dhar, B. B. (2000). Revegetation of a Coal Mine Overburden Dump. In M. Yunus, N. Singh, \& L. J. de kok (Eds.), Environmental Stress: Indication, Mitigation and Eco-conservation (pp. 445448). Dordrecht, Netherlands: Springer.
Solviana, Mukhtar, E., \& Chairul. (2012). Komposisi dan struktur seedling dan sapling pada lahan pra dan pasca tambang batubara PT. SLN di Kabupaten Dharmasraya. Jurnal Biologi Universitas Andalas, 1(2), 123-131.

Sudarmadji, T., \& Hartati, W. (2016). The process of rehabilitation of mined forest lands toward degraded forest ecosystem recovery in Kalimantan, Indonesia. Biodiversitas Journal of Biological Diversity, 17(1), 185-191.

Tistama, R., Siregar, T. H. S., Istianto, Munthe, H., \& Nugroho, P. A. (2009). Usaha pemanfaatan lahan bekas tambang batubara untuk perkebunan karet. Jerami, 2(1), 46-51

World Coal Association. (2015). Coal facts. Diakses dari https://www.worldcoal.org/ sites / default / files / Coa $1 \% 20$ Facts $\%$ 202015.pdf.

Yang, J. E., Skousen, J. G., Ok, Y.-S., Yoo, K.Y., \& Kim, H.-J. (2006). Reclamation of abandoned coal mine waste in Korea using lime cake by-products. Mine Water and the Environment, 25(4), 227-232.

Zhengfu, B., Inyang, H. I., Daniels, J. L., Frank, O., \& Struthers, S. (2010). Environmental issues from coal mining and their solutions. Mining Science and Technology (China), 20(2), 215-223.

Zhenqi, H., Peijun, W., \& Jing, L. (2012). Ecological restoration of abandoned mine land in China. Journal of Resources and Ecology, 3(4), 289-296. 